\title{
Transitive expletive constructions and the object shift parameter
}

\author{
Jan Koster and Jan-Wouter Zwart \\ Groningen University/Department of Linguistics
}

\section{Introduction}

Existential expletive constructions featuring transitive verbs (buy) and unergative intransitive verbs (dance) (hence, transitive expletive construcions or TECs) are attested in a number of Germanic languages (Dutch, Frisian, German, Icelandic), but not in others (English, and the Mainland Scandinavian languages Norwegian, Danish, Swedish):

(1) a. Er heeft iemand een huis gekocht

(Dutch) there has someone a house bought

b. ${ }^{*}$ There has someone bought a house

(English)

(2) a. Er danste iemand

there danced someone

b. ${ }^{\star}$ There danced someone

(English)

It has been noted (by Bures 1992, referred to in Bobaljik and Jonas 1996:210) that the Germanic languages allowing TECs also allow Object Shift (yielding nonadjacency of the verb and its internal argument):

(3) a. ...dat Jan het huis niet kocht

(Dutch) that John the house not bought

b. ${ }^{\star}$ John did the house not buy

This correlation of TECS with Object Shift is unexplained.

In this article, we argue that Koster's (1999a,b) analysis of the difference between Dutch and English as involving individual vs. collective licensing provides a straightforward account of the presence vs. absence of TECs in the two groups of languages. Object Shift occurs only in languages where the elements of the VP are licensed individually, such as Dutch. In English, the elements of the VP are licensed by moving the VP as a whole (pied piping) to the specifier position of TP. As a result, 
the expletive there and the associate someone in (1b) and (2b) compete for the one remaining subject position, the specifier position of AgrSP, and cannot cooccur.

\section{The role of SpecTP}

For the purpose of this article, we assume the basic clause structure illustrated in (4) (cf. Chomsky 1991):

(4)

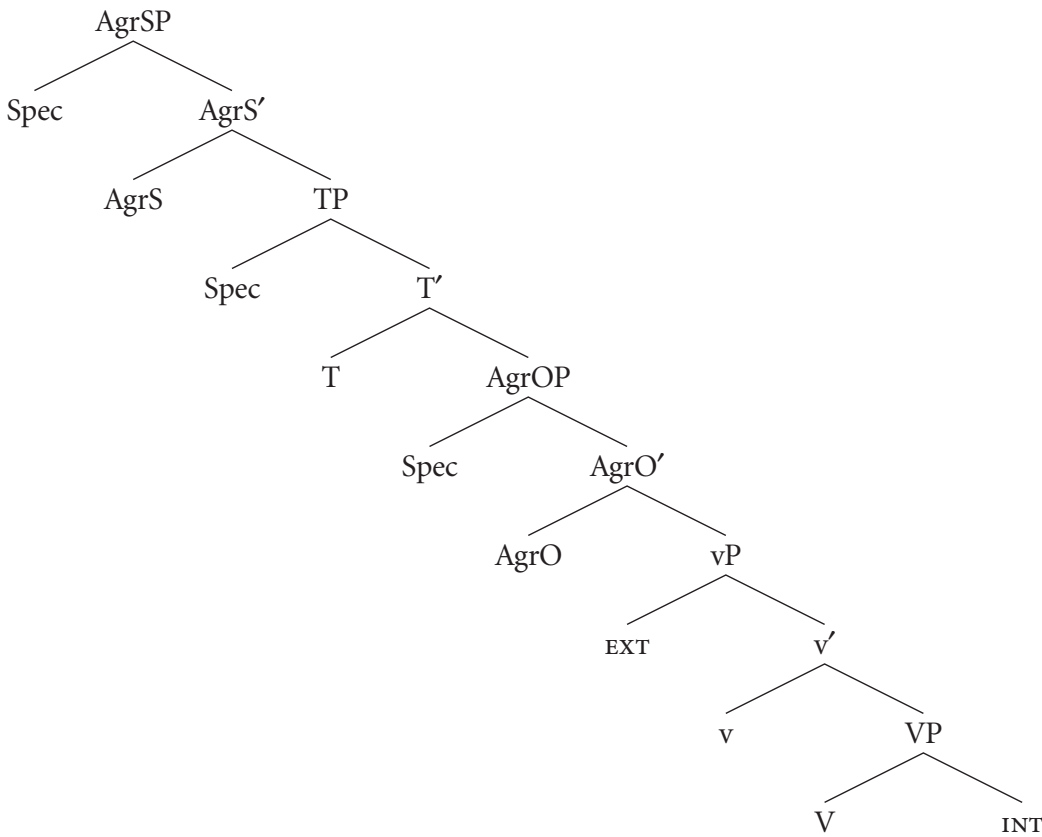

In (4), EXT and INT mark the base positions of the external and internal argument of the verb, and $v$ is a light verb (importing agentive or causative semantics) which is present in transitive and unergative constructions only (cf. Chomsky 1995:315). The internal and external arguments of the verb must be formally licensed as objects or subjects in the specifier positions (spec) of the functional projections AgrSP, TP, and AgrOP. In this approach, SpecTP and SpecAgrSP are both considered to be subject licensing positions, and AgrOP is the object licensing position.

The two subject licensing positions SpecAgrSP and SpecTP are both needed in transitive expletive constructions, where the expletive occupies SpecAgrSP and the associate SpecTP (Jonas 1996: 168; also Zwart 1992:489):

(5) [ ${ }_{\mathrm{AgrSP}}$ Pað byggðu [ $\mathrm{TP}_{\mathrm{P}}$ margir Íslendingar [hús í Pórshöfn]]] (Icelandic) there built many Icelanders houses in Tórshavn 
If this is correct, we may hypothesize that in a language without TECs (e.g. English) one of the two subject licensing positions SpecTP and SpecAgrSP is not available. This hypothesis is investigated in Bobaljik and Jonas (1996), who argue that SpecTP is not available in English, and we concur in assuming as a general starting point the hypothesis in (6):

(6) Absence of TECs indicates nonavailability of SpecTP as a subject licensing position We differ, however, in how we propose to derive the nonavailability of SpecTP.

\section{Deriving the nonavailability of SpecTP}

Bobaljik and Jonas (1996), building on Bures (1992), propose to derive the (non)availability of SpecTP from the theory of local movement - involving a 'Shortest Move' requirement - of Chomsky (1993). According to this theory, the internal and external argument (INT and EXT in (4)), when moving to their licensing positions (one of the spec-positions in (4)), may not cross another spec-position, unless the argument's base position and the intervening spec-position may be considered as 'equidistant' from the targeted licensing position. The situation of equidistance, Chomsky (1993:17-18) proposes, is obtained when the projection containing the argument's base position and the projection containing the intervening spec-position are connected via head movement. Thus, in $(7 \mathrm{a})$ the spec-position of AgrOP intervenes between the base position of the external argument EXT and the spec-position of TP, but in (7b), after head raising from AgrO to T, SpecAgrOP and SpecVP are equidistant from SpecTP, and the external argument may raise from SpecVP to SpecTP without violating the Shortest Move requirement:

(7) a. $\quad\left[\right.$ TP $\operatorname{spec} \mathrm{T}\left[{ }_{\mathrm{AgrOP}} \operatorname{spec}\right.$ AGRO $\left[{ }_{\mathrm{vP}}\right.$ EXT v $\left.\left.\left.[\ldots]\right]\right]\right]$

b. [TP $\operatorname{spec}$ AGRO-T $\left[_{\text {Agrop }} \operatorname{spec} \mathrm{t}_{\mathrm{AgrO}}\left[{ }_{\mathrm{vP}}\right.\right.$ EXT v $\left.\left.\left.[\ldots]\right]\right]\right]$

If head movement is not available as a way to satisfy the Shortest Move requirement, another option exists, namely to simply leave the intervening spec-positions out (Bobaljik and Jonas 1996:200):

(8) $\left[_{\text {AgrSP }}\right.$ spec AGRS $\left[\left[_{\mathrm{TP}} \mathrm{T}\left[\left[_{\mathrm{AgrOP}}\right.\right.\right.\right.$ AGRO $\left.\left.\left.\left[{ }_{\mathrm{vP}} \operatorname{EXT} \mathrm{v}[\ldots]\right]\right]\right]\right]$

The derivations connected with (7) and (8) are radically different. In (8) the external argument moves to its licensing position SpecAgrSP in one step, whereas in (7), the external argument must first land in SpecTP, the only landing site made accessible by the AgrO-to-T movement. That is, a derivation like (9) is not available, as AgrSP and AgrOP are not connected via head movement (i.e., AgrO can only move to $\mathrm{T}$, and the AgrO-T combination can move to AgrS, but AgrO cannot move to AgrS, and hence AgrOP can be connected to TP, but not to AgrSP): 


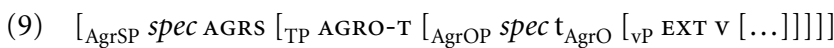

It now follows that if a language generates SpecAgrOP, it must also generate SpecTP. If a language does not generate SpecAgrOP, SpecTP need not be generated, as the derivation in (8) is available. Crucially, SpecAgrOP is generated in all languages featuring Object Shift (movement of the internal argument to SpecAgrOP). As English lacks Object Shift, there is no need to generate SpecTP.

This is how Bobaljik and Jonas (1996) derive the absence of SpecTP in English.

\section{Problems}

We believe that the proposals in Bobaljik and Jonas (1996) are not sufficient to derive the nonavailability of SpecTP in English.

First, their argument shows that all Object Shift languages generate SpecTP. But it does not follow that languages without Object Shift, such as English, must not generate SpecTP.

Second, we know that the verb movement illustrated in (7b), making SpecTP available, is equally present in Continental West Germanic languages (Dutch, Frisian, German) and Mainland Scandinavian languages (Danish, Norwegian, Swedish). Following Zwart (1997a), we assume that it takes place overtly in main clauses, and covertly (i.e. by way of feature movement) in embedded clauses. Others, e.g. Vikner (1995), have argued that it takes place in main clauses only. Either way, the two groups of languages behave the same. Yet Continental West Germanic allows TECs, and Mainland Scandinavian does not.

Third, Bobaljik and Jonas' (1996) argument is hard to recast in the framework of Chomsky (1995:Section 4.10), where the AgrSP and AgrOP of (4) have been eliminated, and the specifiers of these projections are redefined as outer specifiers of TP and vP, respectively. In this system, SpecTP is always present, and the question becomes why TP has two specifier positions in some languages, such as Dutch, but only one in others, like English. Chomsky's (1995:354) solution to that problem is to simply stipulate that Dutch type languages may 'check the EPP feature twice' (i.e. may have two subjects).

Fourth, expletive constructions in Dutch and English differ in a number of other aspects, in addition to the valency of the verb (cf. Zwart 1991). Thus, Dutch, but not English, allows impersonal passives (10), a 'strong', partitive reading of the associate (11) (de Hoop 1990:280), and individual level predication over the associate (12) (de Hoop 1992:171):

(10) a. Er werd gedanst

(Dutch) there was danced

b. ${ }^{*}$ There was danced 
(11) a. ...dat er veel katten in de tuin zijn

(Dutch) that there many cats in the garden are (existential/partitive)

b. There are many cats in the garden (English) (existential $/{ }^{*}$ partitive)

(12) a. Er zijn veel mensen ziek/intelligent (Dutch) there are many people sick/intelligent

b. ${ }^{\star}$ There are many people sick $/{ }^{*}$ intelligent (English)

Bobaljik and Jonas' (1996) explanation for the distribution of TECs sheds no light on these differences.

In the remainder of this article, we propose an alternative way of deriving the nonavailability of SpecTP in English. Like Bobaljik and Jonas (1996), we believe that the key to our understanding of the differences between languages with and without TECs lies in the observation that (within Germanic) the group of TEC languages and the group of Object Shift languages coincide ('Bures' Generalization'). The question is, why.

\section{The Object Shift Parameter}

In Koster (1999a,b) a general proposal is made to explain the difference between English-type vo languages and ov languages like Dutch and German. This proposal builds further on the hypothesis of Zwart (1994) that Germanic ov orders are derived from an underlying (universal) vo order through Object Shift to SpecAgrOP (cf. (4)) (see Vanden Wyngaerd 1989). This theory explains, among other things, that ov order is strongly correlated with Object Shift (Corver and Van Riemsdijk 1997; Zwart 1997b:255).

A less satisfactory aspect of the theory of Zwart (1994) was that the occurrence of Object Shift was made dependent on an arbitrary characterization of AgrO as 'strong' (in case of ov order, as in Dutch) or 'weak' (in case of vo, as in English). This arbitrary parametrization did not provide any further insight.

According to the proposal made in $\operatorname{Koster}(1999 \mathrm{a}, \mathrm{b})$ there is no such thing as a weak-strong parametrization, and all Germanic languages (ov and vo) show overt movement to $\operatorname{AgrO}(\mathrm{P})$ and $\mathrm{T}(\mathrm{P})$, the domains where the internal argument is licensed and the verb's tense feature are checked. We would like to propose the following generalization:

(13) Pied Piping parameter distinguishing English from Dutch

Dutch checks its VP-internal constituents individually (by moving them separately), English collectively (by moving the whole VP)

Although it is by no means clear why languages differ in this respect, it is generally 
agreed upon that languages do differ with respect to pied piping. Thus, in American English, wh-movement involves a minimal wh-phrase (14a), whereas in British English $w h$-movement may involve the entire PP containing the wh-phrase (14b):

(14) a. Who did you talk $\left[{ }_{\mathrm{PP}}\right.$ to $\left.t_{\mathrm{i}}\right]$ ?

b. $\quad[\mathrm{PP} \text { To whom }]_{\mathrm{i}}$ did you talk $t_{\mathrm{i}}$ ?

It appears that in this respect, there is quite a bit of variation among the languages of the world, and in several cases even whole clauses can be pied piped (see, for instance, Van Riemsdijk 1994).

The 'scrambling' we see in languages like Dutch and German is just a result of the circumstance that the individual heads and phrases are 'scattered' over the clause by individual movement to their licensing positions. It is now explained rather than stipulated that English does not show the Dutch type leftward Object Shift (cf. (3b)). Since the whole VP is moved through SpecAgrOP to SpecTP, these spec positions can no longer serve as landing sites for individual phrases:

(15) Collective Checking (VP-movement) in English

$\left[\right.$ AgrSP SUBJECT AGRS $\left[{ }_{\mathrm{TP}}\left[{ }_{\mathrm{VP}} \mathrm{V} \text { OBJECT }\right]_{\mathrm{i}} \mathrm{T}\left[{ }_{\text {AgrOP }} t_{\mathrm{i}}\right.\right.$ AGRO $\left.\left.\left.\left[{ }_{\mathrm{vP}} v t_{\mathrm{i}}\right]\right]\right]\right]$

In (15), the object is licensed via pied piping when the VP moves through SpecAgrOP. Similarly, the verb checks its tense features when the VP moves to TP. The only DP that can be moved by itself — because it is not a VP internal element, cf. (4) - is the subject, which is licensed in SpecAgrSP. (We remain somewhat agnostic about the exact dimension of the verb phrase moving in the process of collective licensing in English. If the verb is in $v$, the consituent moving is actually $v^{\prime}$, excluding the external argument, or $v P$ if external argument extraction can somehow take precedence. The general idea is that what moves is a 'predicate', in the sense of a verb with its internal arguments and perhaps some local adverbial material.)

As can be seen in (15), licensing of the VP-internal elements via pied piping has the result that only one subject position is available in English, namely Spec, AgrSP. This explains the absence of TECs in English, which we assume - with Bobaljik and Jonas 1996-to follow from the nonavailability of the second subject position (SpecTP). Our theory mainly differs as to the nature of the nonavailability of the second subject position.

Ov languages like Dutch differ from English in that the spec positions 'visited' by the VP in (15) are filled by the individual VP constituents (e.g. the object DP; in (16), movement of the verb is ignored):

(16) Individual Checking in Dutch

$$
\text { [AgrSP SUbJeCt AGRs [TP } \left.\left.\mathrm{T}\left[\text { Agrop OBJECT AGRo }\left[{ }_{\mathrm{vP}} v\left[{ }_{\mathrm{VP}} \mathrm{V}\right]\right]\right]\right]\right]
$$

This has the result that the spec position of TP is not occupied by the VP (as in English), so that both SpecAgrSP and SpecTP are available as subject positions. In 
other words, individual checking of DPs explains the correlation between the occurrence of TECs and Object Shift.

Our theory avoids the problems discussed in Section 4 above with respect to the proposal of Bobaljik and Jonas (1996) (see Section 7 below) and Chomsky's (1995:354) unmotivated stipulation that Dutch-type languages may 'check the EPP feature twice' (in order to allow two subject positions).

\section{Summary of independent evidence}

In fact, our theory was developed in complete independence of the problem at hand. It is the only theory, so far, that explains the correlation between ov order and leftward Object Shift among the Germanic languages. Moreover, it replaces the arbitrary weak-strong distinction of earlier theories by a pied piping difference, an ill-understood but unavoidable dimension along which languages are generally believed to differ.

Independent evidence supporting our theory can be found in the distribution of adverbs in English and Dutch. For present purposes, we make the simplifying assumption that adverbials come in two broad classes, namely sentence adverbials like probably and VP-adverbials like yesterday (see Alexiadou 1997 and Cinque 1998 for recent, more refined theories of adverbial structure). We make the more or less standard assumption that sentence adverbials $\left(A d v_{1}\right)$ are outside TP and VP-adverbials $\left(A d v_{2}\right)$ outside VP:

$$
\left.\left[_{\mathrm{AgrSP}} \operatorname{AGRS}\left[A d v_{1}\left[\mathrm{TP}_{\mathrm{TP}} \mathrm{T}\left[\mathrm{AgrOP} \text { AGRO [ } A d v_{2}\left[{ }_{\mathrm{vP}} v[\mathrm{VP} \mathrm{v}]\right]\right]\right]\right]\right]\right]
$$

Our theory explains part of the interesting and otherwise mysterious distribution of adverbials in English, since it predicts that the VP ends up between the two classes of adverbials. In other words, we have a principled explanation for the fact that adverbs of class $\operatorname{Adv}_{1}$ (like probably) can still precede the VP, while adverbials like yesterday $\left(\mathrm{Adv}_{2}\right)$ can only follow (cf. Koster 1999a, b):

(18) a. He probably [vp saw Bill]

b. ${ }^{*}$ He yesterday [Vp saw Bill]

c. He [vp saw Bill] yesterday

Another remarkable fact is that English adverbial order shows certain scope paradoxes and irregularities as to the correlation of scope and linear order. In languages like Dutch, a strict correlation exists between scope and linear order (to the left of the verb in embedded ov structures). In English, we often see the same, as in (18a): probably has wider scope than the VP. However, this 'regular' correlation between scope and linear order breaks down in English examples like the following: 
(19) a. He worked hard yesterday

b. ${ }^{\star}$ He worked yesterday hard

Yesterday has wider scope than hard, in spite of the fact that it follows rather than precedes. This makes English an apparent irregular language with respect to the correlation linear order-scope. In an ov language like Dutch, everything seems regular because the element with wider scope (gisteren 'yesterday') precedes the element with narrower scope (hard):

(20) a. ...dat hij gisteren hard werkte that he yesterday hard worked '...that he worked hard yesterday'

b. *...dat hij hard gisteren werkte that he hard yesterday worked

Assuming that hard is a VP-internal constituent, our hypothesis makes English 'regular' as well because in the underlying order, the VP is to the right of the adverbial yesterday ((21a), cf. (15)). Since the whole VP must be moved for purposes of licensing (in this case to the SpecTP for checking the verb's tense features), we end up with (19a) as a derived structure (21b):

(21) a. [yesterday [ ${ }_{\mathrm{vP}}$ he $v$ [ [VP worked hard]]]

b. $\quad$ He $\left[_{\mathrm{TP}}\left[{ }_{\mathrm{VP}} \text { worked hard }\right]_{\mathrm{i}} \mathrm{T}\right.$ [yesterday $\left.\left.\left[{ }_{\mathrm{vP}} t_{\mathrm{i}}\right]\right]\right](=(19 \mathrm{a}))$

Importantly, some of the adverb placement facts of English could also be explained by assuming individual movement to the left of the verb and its internal arguments (e.g. Johnson 1991). However, such an analysis needs additional stipulations to account for the fact that in English the verb and its internal argument are strictly adjacent. This adjacency follows from the analysis proposed here, as the verb and its internal argument are displaced as a constituent.

For reasons of space, this is only a simplified summary of some crucial new explanations following from our hypothesis of collective feature checking by VP pied piping. (It will be seen, for instance, that our theory offers an alternative to Pollock's (1989) explanation of the English-French contrast in (22) as well:
a. Jean embrasse souvent Marie
b. John ( ${ }^{*}$ kisses) often (kisses) Mary

In English (22b), but not in French (22a), the verb and its internal argument cannot be separated, as the VP-internal elements are licensed collectively via VP-movement. It remains to be explained, however, how the placement of auxiliaries can be reconciled with the collective licensing proposal.) For further details, the reader is referred to Koster (1999a, b).

Given the fact that our hypothesis is independently motivated and explains several otherwise mysterious facts, we propose that the procedure of VP pied piping 
to SpecAgrOP and SpecTP is the very mechanism explaining the nonavailibility of the second subject position, SpecTP, in English. Following the pattern of explanation (but not the details) proposed by Bobaljik and Jonas, we explain the remarkable correlation between Object Shift and the TEC facts.

\section{Some further facts}

Our hypothesis avoids the problems noted above in Section 4, and makes some interesting further predictions.

The core of the explanatory pattern we have proposed so far is that of the two potentially available subject positions (the spec positions of AgrSP and TP, cf. (4)), the second (SpecTP) is no longer available for DPs in languages like English since it is occupied by the VP. This makes the strong prediction that not only TECs but all other constructions requiring two subject positions are excluded in English-type languages.

Thus, impersonal passives are possible in languages with Object Shift and TECS (like Dutch), but not in languages with VP pied piping like English:
a. Er werd gedanst
there was danced
b. ${ }^{\star}$ There was danced

The explanation of this correlation is straightforward under our assumptions if we assume, as in Koster (1987:261), that impersonal passives like (23a) involve an empty noun phrase associate to the locative expletive er 'there':

(24) Er werd $\left[{ }_{\mathrm{DP}} e\right]$ gedanst

This analysis is based on the idea that locative expletives like er need a nominal associate to fulfill the subject role and that this nominal associate (an empty subject) must be licensed in a subject position. This subject position, SpecTP, is available in Dutch (25a), but not in English (25b):

$$
\begin{array}{ll}
\text { a. } & \text { Er werd }\left[{ }_{\mathrm{TP}}\left[{ }_{\mathrm{DP}} e\right]\right] \mathrm{T}\left[{ }_{\mathrm{VP}} \ldots \text { gedanst...] }\right] \\
\text { b. } & {\left[{ }_{\mathrm{NP}} \text { There }\right] \text { was }\left[{ }_{\mathrm{TP}}\left[{ }_{\mathrm{VP}} \text { danced }\right]_{\mathrm{i}} \mathrm{T}\left[{ }_{\mathrm{VP}} t_{\mathrm{i}}\right]\right]}
\end{array}
$$

Notice that the Mainland Scandinavian languages (Danish, Norwegian, Swedish), who side with English in disallowing Object Shift and TECs, do allow impersonal passives (Koch Christensen 1991:53, Vikner 1995:209):

$$
\begin{aligned}
& \text { Det ble klaget } \\
& \text { it PASs.Aux complained }
\end{aligned}
$$

Here, however, the expletive is not locative, and may fulfill the subject role without support of an associate. (Danish differs from Norwegian and Swedish in employing 
the locative expletive der in these constructions, leaving us with a problem for further research.)

In general, constructions introduced by there in English can only be followed by a subject if the subject is internal to the VP, so that it can participate in collective checking through the VP:

(27) There [VP are [SC many cats in the garden]

In this example, the subject many cats is not external to the VP but internal to its Small Clause complement, as indicated by the bracketing. In the Dutch counterpart to (27), however (cf. (11)), veel katten 'many cats' can be in the spec of TP (Zwart 1992:489), which leads to the differences in interpretation noted above in (11)-(12).

The relevant facts follow from our proposal, on the common assumption that VP-internal elements receive an existential interpretation (Diesing 1990; de Hoop 1992). In English, the internal argument is stuck inside VP throughout the derivation, and cannot escape existential interpretation. In Dutch, the internal argument moves out of VP and can take on a 'strong', partitive reading in SpecTP. (We have to assume that existential interpretation is available for elements outside VP as well, in order to derive the weak reading of (11a); see Koster 1994 and Zwart 1995 for discussion.) As individual level predication over an indefinite subject (cf. (12)) is only possible if the indefinite gets a partitive interpretation (de Hoop 1992:171f), the facts in (12) reduce to those in (11).

In short, the analysis proposed here does not encounter the problems connected with the Bobaljik and Jonas analysis noted in Section 4. In addition, our proposal connects the further differences between English and Dutch in the domain of expletive constructions listed in (10)-(12) to the single parameter needed to account for the distribution of TECS, the parameter of individual vs. collective licensing.

We may add a further observation in support of our analysis. Our argument rests on the assumption that of the two subject positions, SpecAgrSP and SpecTP (cf. (4)), only SpecAgrSP is available for DPs. This leaves open the possibility that the associate in English is licensed in a position other than SpecAgrSP or SpecTP. We believe that this possibility is instantiated in examples like (28), discussed in Chomsky (1995:343):

(28) a. There hit the stands a new journal.

b. There visited us last night a large group of people who traveled all the way from India.

The italicized associates in (28) are clearly in a different kind of position from the associates in the Dutch examples discussed so far (as evidenced by the sentence final position). We would like to propose that these 'heavy noun phrases' are extracted to a focus position to the immediate left of the VP, followed by VP movement across the focus position to TP, as discussed above. In this type of derivation, the 
subject would be licensed in the focus position, and the nonavailability of SpecTP would be irrelevant. Precisely in these circumstances, then, does English seem to allow TECs. This strengthens the starting point of our analysis, namely that the key factor in our understanding of the distribution of TECs is the availability of SpecTP.

\section{Conclusion}

In this article we have argued that the correlation between the distribution of transitive expletive constructions and Object Shift in Germanic (+TEC/os: Dutch, German, Frisian, Icelandic; -TEC/os: English, Mainland Scandinavian) is explained on the assumption that VP-internal elements move individually in the + group and collectively in the -group. As a result, SpecTP is available for noun phrases in Dutch etc., creating the possibility of TECs with the associate noun phrase in SpecTP, but not in English etc., where SpecTP is occupied by the VP. The analysis also accounts for further differences w.r.t. expletive constructions in the two groups of languages, notably the occurrence of impersonal passives and the possibility of nonexistential interpretations of the associate noun phrase.

Though further research is needed to assess the wider implications of the proposal, we feel it gains support in that it allows us to replace stipulated differences among languages with a single independently established dimension of variation: individual vs. collective licensing.

\section{References}

Alexiadou, A. (1997) Adverb placement: a case study in antisymmetric syntax. Benjamins, Amsterdam. Bobaljik, J.D. and D. Jonas (1996) 'Subject positions and the roles of TP.' Linguistic Inquiry 27, 195-236.

Bures, T. (1992) '(Re)cycling expletives and other sentences.' Ms., MIT.

Chomsky, N. (1991) 'Some notes on economy of derivation and representation.' In Chomsky (1995).

Chomsky, N. (1993) 'A minimalist program for linguistic theory.' In Chomsky (1995).

Chomsky, N. (1995) The minimalist program, MIT Press, Cambridge.

Cinque, G., J. Koster, J.-Y. Pollock, L. Rizzi and R. Zanuttini, eds. (1994) Paths towards Universal Grammar: studies in honor of Richard S. Kayne, Georgetown University Press, Washington DC.

Cinque, G. (1998) Adverbs and functional heads: a cross-linguistic perspective. Oxford University Press, New York.

Corver, N. and H.C. van Riemsdijk (1997) 'The position of the head and the domain of scrambling.' In B. Palek, ed., Typology: prototypes, item orderings and universals, Charles University, Prague.

De Hoop, H. (1990) 'Restrictions on existential sentences and object scrambling: some facts from Dutch.' Proceedings of WCCFL 9, 277-288. 
De Hoop, H. (1992) Case configuration and noun phrase interpretation. Dissertation, University of Groningen.

Diesing, M. (1990) The syntactic roots of semantic partitioning. Dissertation, University of Massachusetts, Amherst.

Johnson, K. (1991) 'Object positions.' Natural Language and Linguistic Theory 9, 575-633.

Jonas, D. (1996) 'Clause structure, expletives, and verb movement.' In W. Abraham, S. D. Epstein, H. Thráinsson, and C.J.W. Zwart, eds., Minimal ideas: syntactic studies in the minimalist framework, Benjamins, Amsterdam.

Koch Christensen, K. (1991) 'Complex passives reanalyzed.' Working Papers in Scandinavian Syntax 48, 45-75.

Koster, J. (1987) Domains and dynasties: the radical autonomy of syntax. Foris, Dordrecht.

Koster, J. (1994) 'Predicate incorporation and the word orders of English and Dutch.' In Cinque et al.

Koster, J. (1999a) 'The word orders of English and Dutch: Collective vs. individual checking.' Groninger Arbeiten zur germanistischen Linguistik 43, 1-42.

Koster, J. (1999b) 'Pied Piping and the word orders of English and Dutch.' To appear in Proceedings of NELS 30, GLSA, Amherst.

Pollock, J.-Y. (1989) 'Verb movement, Universal Grammar, and the structure of IP.' Linguistic Inquiry 20, 365-424.

Van Riemsdijk, H. C. (1994) 'Another note on clausal pied-piping.' In Cinque et al.

Vanden Wyngaerd, G. (1989). 'Object Shift as an A-movement rule.' MIT Working Papers in Linguistics 11, 256-271.

Vikner, S. (1995) Verb movement and expletive subjects in the Germanic languages. Oxford University Press, New York.

Zwart, C.J.W. (1991) 'Expletive raising and expletive replacement in Dutch.' Proceedings of the Eastern States Conference On Linguistics 8, 393-404.

Zwart, C. J.W. (1992) 'Dutch expletives and Small Clause predicate raising.' Proceedings of NELS $22,477-491$.

Zwart, C. J. W. (1994) 'Dutch is head initial.' The Linguistic Review 11, 377-406.

Zwart, C.J.W. (1995) 'Word order, intonation, and noun phrase interpretation in Dutch.' Proceedings of WECOL 7, 279-289.

Zwart, C.J.W. (1997a) Morphosyntax of verb movement: a minimalist approach to the syntax of Dutch.Kluwer Academic Publishers, Dordrecht.

Zwart, C.J.W. (1997b) 'The Germanic SOV languages and the Universal Base Hypothesis.' In L. Haegeman, ed., The New Comparative Syntax, Longman, London. 